\title{
New year's greeting from the ESNR
}

\author{
Paul M. Parizel • Guido E. Wilms
}

Published online: 22 December 2010

(C) Springer-Verlag 2010

From 2006 to 2010, Prof. James Byrne (Oxford, UK), served as editor-in-chief of Neuroradiology, the official journal of the European Society of NeuroradiologyDiagnostic and Interventional (ESNR). Under his leadership, and thanks to his innovative ideas, the impact factor of Neuradiology increased from 1,488 in 2005 to 2,616 in 2009. In the ranking of radiological journals, Neuroradiology rose from position 44 (out of 84) in 2005 to position 31 (out of $104)$ in 2009. These changes reflect the increase of quality in scientific content, which improved the standing of Neuroradiology in comparison with other radiological journals. As secretary-general of the ESNR and as the new editor-in-chief, (GW) and incoming president of the ESNR and secretarygeneral of the World Federation of Neuroradiological Societies (PP), we want to thank James Byrne for his efforts, and congratulate him with this outstanding achievement. We would also like to thank and congratulate the hard-working section editors, managing editor, and reviewers, without whose invaluable help, this success could never have been achieved.

It is not by coincidence that the new editor-in-chief of Neuroradiology is also a member of the Executive Committee of ESNR. Neuroradiology is the official journal of ESNR, and it should reflect the ideas and philosophy of our society and of our discipline. Our Journal needs to reflect the leadership role of ESNR in establishing standards of training and practice in diagnostic

\section{P. M. Parizel}

Dept. of Radiology \& Neuroradiology,

Antwerp University Hospital,

Wilrijkstraat 10 ,

2650 Edegem, Belgium

\section{G. E. Wilms $(\bowtie)$}

Department of Radiology, UZ-Gasthuisberg,

Herestraat 49,

3000 Leuven, Belgium

e-mail: guido.wilms@uz.kuleuven.ac.be and interventional neuroradiology. We must assume responsibility in the teaching and education of young neuroradiologists in- and outside Europe, we must stimulate scientific research, and we must encourage our colleagues to submit their best work for publication in Neuroradiology.

Thanks to the strategic leadership of the late Prof. Pierre Lasjaunias, Prof. Olof Flodmark, Prof. Martin Schumacher, and Prof. Marco Leonardi (all former presidents of ESNR and members of the former European Board of Neuroradiology), a Division of Neuroradiology was created within the UEMS Section of Radiology in 2008. Under the presidency of Prof. Olof Flodmark, this division will determine and finalize the standards of training in diagnostic and interventional neuroradiology in close collaboration with the scientific committees of ESNR.

Education in Neuroradiology remains a main objective of our society. We are therefore very happy and proud to announce the creation of the European School of Neuroradiology (ESONR), mainly thanks to the vision of our former President, Prof. Marco Leonardi. The ESONR will offer three levels of courses to all those interested in Neuroradiology. The first level consists of basic "Galen" courses in Neuroradiology, which are organized in conjunction with the European School of Radiology (ESOR). The second level, which is the cornerstone of our educational activities, is the European Course in Neuroradiology (ECNR), which has been successfully organized since 1984, and remains dedicated to the memory of one of its founders, Pierre Lasjaunias. The third level consists of advanced courses of higher qualification in the different subspecialities in Neuroradiology including, among others, Interventional Neuroradiology and Paediatric Neuroradiology.

ESNR aims to stimulate scientific excellence in neuroradiology by awarding prizes to the very best and creative researchers during the annual congress of ESNR. 
This goal is reflected in the two "Founders of European Neuroradiology Awards": one for diagnostic and one for interventional neuroradiology, as well as in the "Lucien Appel Prize of the ESNR" for scientific research.

Finally, under the impulse of Prof. Marco Leonardi, ESNR has opened the door to "Institutional Membership". We hope that national neuroradiological societies will join ESNR and provide institutional membership of ESNR to their national members. We are convinced that, in this way, more neuroradiologists throughout Europe and beyond, can become members of ESNR. This will further strengthen our discipline, our society, and our journal. In this way, Neuroradiology will continue to be one of the pillars "stimulating creativity in scientific research" as the founders of the European Society of Neuroradiology formulated their ambition in the original statement at the foundation of the society in 1969.

Neuroradiology is not only the official journal of the ESNR, but also of the Japanese Neuroradiological Society and of many European National Societies and Sections of Neuroradiology.

We hope that not only neuroradiologists from Europe and Japan, but also from other countries and continents, will continue to be inspired by the commitment of so many and work together to make our society and our journal better and stronger. 